\title{
Financial stability under model uncertainty
}

\author{
Zeynep Kantur, Gülserim Özcan * \\ Department of Economics, Bilkent University, Ankara 06800, Turkey
}

\section{H I G H L I G H T S}

- Optimal monetary policy is designed to guard against potential asset-price bubble.

- Financial stabilization target dampens the financial wealth-effect on consumption.

- Model uncertainty speak to more active policymaking.

\section{A R T I C L E I N F O}

\section{Article history:}

Received 28 May 2018

Received in revised form 17 August 2018

Accepted 23 September 2018

Available online 27 September 2018

\section{JEL classification:}

D81

E44

E52

E58

Keywords:

Asset price

Robust control

Model uncertainty

Optimal monetary policy

\begin{abstract}
A B S T R A C T
This paper studies how asset price model misspecification affects the conduct of monetary policy under commitment in a New Keynesian model using robust control techniques. We find that monetary policy reacts aggressively to both asset price and inflation shocks to guard herself against worst-case outcome.
\end{abstract}

(C) 2018 Elsevier B.V. All rights reserved.

\section{Introduction}

Large fluctuations in financial markets might lead to macroeconomic instability, especially when asset prices deviate from their fundamentals. Whether to consider these fluctuations as a policy concern has been a long-standing discussion in monetary policy literature. ${ }^{1}$ The 2008-2009 financial crisis is a watershed moment for the central banks. Since then, financial stability has become an imperative policy concern for policymakers and calls for an intervention to counteract the episode of asset price inflation. Woodford (2012) and Galí (2014) prescribe integrating financial stability as an explicit mandate into monetary policy. The consensus among these papers is to respond financial instability preemptively by temporarily diverging from inflation and output-gap objectives of the central bank $(\mathrm{CB})$.

\footnotetext{
* Corresponding author.

E-mail address: gulserim@bilkent.edu.tr (G. Özcan).
}

1 Bernanke and Gertler (2001) and Gilchrist and Leahy (2002) claim that asset prices fluctuations should not stand as a policy concern of an inflation targeting central bank. On the other hand, Lowe and Borio (2002) and Cecchetti et al. (2002) are among the early supporters of the opposite view.
One of the main difficulties in targeting financial stability is to detect and measure asset price bubbles with certainty. Gürkaynak (2008) addresses this issue by providing a summary of existing models and techniques. Nevertheless, lack of methods does not mean to disregard the case for including asset price fluctuations in the conduct of monetary policy, and it is crucial to acknowledge this sort of uncertainty in a theoretical analysis of monetary policy.

In this paper, in a dynamic general equilibrium model with asset prices, we formulate optimal monetary policy under commitment when the policymaker is uncertain about structure of the asset prices. We use robust control techniques suggested by Hansen and Sargent (2008) to obtain policies that are robust against model uncertainty. The aforementioned empirical discussion about asset price uncertainty corresponds well with the underlying idea of the technique. Robust control enables policymaker to design optimal policy which performs well even under the worst possible scenario.

The closest paper to ours is Dai and Spyromitros (2012) where closed-form solutions for optimal policy under a discretionary environment is derived. However, analyzing robust optimal policy when the monetary authority can commit is a contribution since 
worst-case analysis works through its impact on expectation formation as a deviation from the rational expectations. This framework enables us to obtain richer model dynamics in response to persistent shocks.

The rest of the paper is organized as follows. The next section describes the model. Section 3 provides results and discussion. Section 4 concludes.

\section{The model}

We utilize the New Keynesian model by Nistico (2012) where the demand side of the economy is the stochastic version of the perpetual-youth model introduced by Blanchard (1985) and Yaari (1965). This framework provides room for discussing the stance of monetary policy in the presence of asset price dynamics. The economy is described by the following equations:

$$
\begin{aligned}
x_{t} & =\frac{1}{1+\psi} E_{t} x_{t+1}+\frac{\psi}{1+\psi} q_{t}-\frac{1}{1+\psi}\left(r_{t}-E_{t} \pi_{t+1}\right) \\
q_{t} & =\tilde{\beta} E_{t} q_{t+1}-\lambda E_{t} x_{t+1}-\left(r_{t}-E_{t} \pi_{t+1}\right)+\epsilon_{t}^{q} \\
\pi_{t} & =\tilde{\beta} E_{t} \pi_{t+1}+\kappa x_{t}+\epsilon_{t}^{\pi}
\end{aligned}
$$

where $x, \pi, q$ and $r$ denote output-gap, inflation rate, asset price, and nominal interest rate. $\epsilon_{t}^{q}$ is a shock accounting for deviations of asset price from its fundamental value. $\epsilon_{t}^{\pi}$ is a cost-push shock to firms.

In this model, $\tilde{\beta} \equiv \beta /(1+\psi)$ is the stochastic discount factor which deviates from the intertemporal discount factor, $\beta$, because the duration of staying active in the financial market is shorter than the lifespan of an agent. As this duration gets longer, $\tilde{\beta}$ converges to $\beta$ and the model collapses to representative agent framework.

Eq. (1) is the IS equation which relates current output-gap to expectations of future output-gap, real interest rate, and current value of asset price. The presence of $q_{t}$ represents the financial wealth channel in real side of the economy. Eq. (2) shows asset price dynamics. Asset price evolves with its own future value, expected output-gap and the real interest rate. Eq. (3) is forwardlooking Phillips relation.

Shocks are assumed to follow stationary autoregressive processes:

$\epsilon_{t}^{i}=\rho_{i} \epsilon_{t-1}^{i}+v_{t}^{i}, \quad v_{t}^{i} \sim$ i.i.d. $\quad N(0,1), \quad i \in\{q, \pi\}$

where $\rho_{i}$ is the persistence of shocks.

\subsection{Model uncertainty}

Model uncertainty is introduced by a second type of disturbance $w_{t}$ in the asset price shock as in Hansen and Sargent (2008):

$\epsilon_{t}^{q}=\rho_{q} \epsilon_{t-1}^{q}+\left[v_{t}^{q}+w_{t}\right]$.

To represent the idea that the distorted model is not far from the reference model, the misspecification is assumed to be bounded by a parameter $\eta_{0}$ as follows:

$E_{t} \sum_{\tau=0}^{\infty}\left[w_{t+\tau}\right]^{2} \leq \eta_{0}, \quad \eta_{0}>0$.

\subsection{Robustly optimal monetary policy}

In perpetual-youth model, the interaction in the financial markets of heterogeneous agents begets a distortion in the crosssectional consumption distribution across households. This distributional distortion attributes a critical role to financial stability.
Therefore, an optimal design of monetary policy requires incorporating financial stability as an explicit target besides inflation and output. $^{2}$

We assume the following period loss function for the $\mathrm{CB}$ :

$L_{t}=\pi_{t}^{2}+\lambda_{x} x_{t}^{2}+\lambda_{q} q_{t}^{2}+\lambda_{r}\left(\Delta r_{t}\right)^{2}$

where $\lambda_{x}, \lambda_{q}, \lambda_{r}>0$ are relative weights of output-gap stability, financial stability, and interest rate smoothing respectively.

A hypothetical evil agent is introduced to formulate the problem under model misspecification. While the CB tries to minimize the loss function (7), evil agent distorts the model as much as possible by maximizing the same objective function. Hence the problem can be represented by a Stackelberg-game: the evil agent chooses a model from the available set of alternative models and the $\mathrm{CB}$ designs policy optimally to perform well in the worst-case scenario. lem:

The game is represented by the following extremization prob-

$\min _{\left\{x_{t}, q_{t}, \pi_{t}, r_{t}\right\}_{t=0}^{\infty}} \max _{\left\{w_{t+1},\right\}_{t=0}^{\infty}} \frac{1}{2} E_{t} \sum_{t=t_{0}}^{\infty} \beta^{t}\left[L_{t}-\beta \theta w_{t+1}^{2}\right]$

subject to the distorted model (1), (2), (3), (5), and the entropy constraint (6). Here, $0<\theta<\infty$ represents the monetary authority's preference for the degree of model misspecification. $\theta$ can be interpreted as a Lagrange multiplier on the constraint (6) which is positively related to $\eta_{0}^{-1}$.

We have three possible equilibria in this setting: (i) rational expectations, (ii) worst-case and (iii) approximating. We take $r a-$ tional expectations equilibrium as the benchmark in which there is no concern for model uncertainty and no distortion in the model. In worst-case equilibrium, there is a concern for model uncertainty and the policymaker sets the policy rule under the distorted model. In approximating equilibrium, the concern for model uncertainty still exists, therefore the policymaker uses the robust policy. However, this time there is no distortion in the model. The rational expectations and the approximating equilibrium share the same shock process dynamics; however, they differ in their policy functions. In this setting, the worst-case solution is used as a tool to obtain the approximating equilibrium. The idea is to design policy to insure against catastrophic outcomes.

\section{Results and discussion}

Figs. 1 and 2 show responses of the variables to one standard deviation of an asset price shock and a cost push shock under the benchmark model with rational expectations, worst-case model, and approximating model. ${ }^{3}$

A positive asset price shock is accompanied by an increase in the interest rate due to the financial stabilization objective of the policymaker. Monetary authority responds by increasing the policy rate gradually acknowledging the impact of her actions on expectations of future variables under commitment and the interest rate inertia in her objective function. Under commitment, the CB stabilizes the economy not only by controlling the current output-gap and asset prices but also by promising to keep them lower in the future. Although the increase in asset prices is expected to have a

\footnotetext{
2 See Nistico (2016) for the derivation of a welfare-based loss function for a similar model.

3 Calibration values of the parameters are mainly taken from the literature as follows: $\beta=0.99, \psi=0.03, \lambda=0.31, \kappa=0.18, \rho_{q}=\rho_{\pi}=0.8, \lambda_{x}=0.5$ $\lambda_{q}=0.25, \lambda_{r}=0.1$. In order to quantify the degree of uncertainty aversion, we adopt the concept of a detection error probability (DEP). We set $\theta=1450$ which corresponds to a detection error probability of $20 \%$ in a sample of 240 observations. For a detailed discussion of DEP see, for instance, Anderson et al. (2003) and Hansen and Sargent (2008).
} 

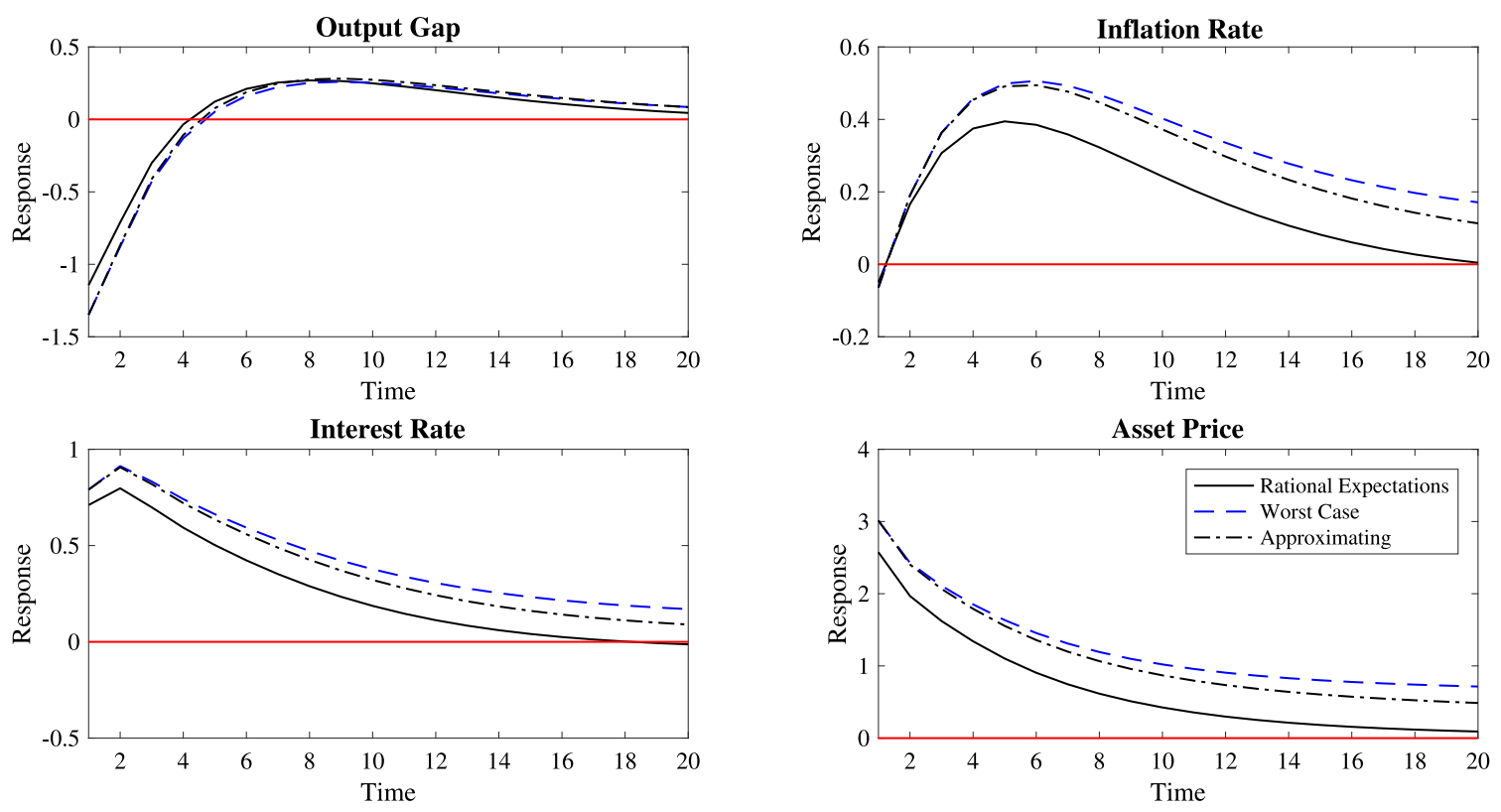

Fig. 1. Responses to asset-price shock.
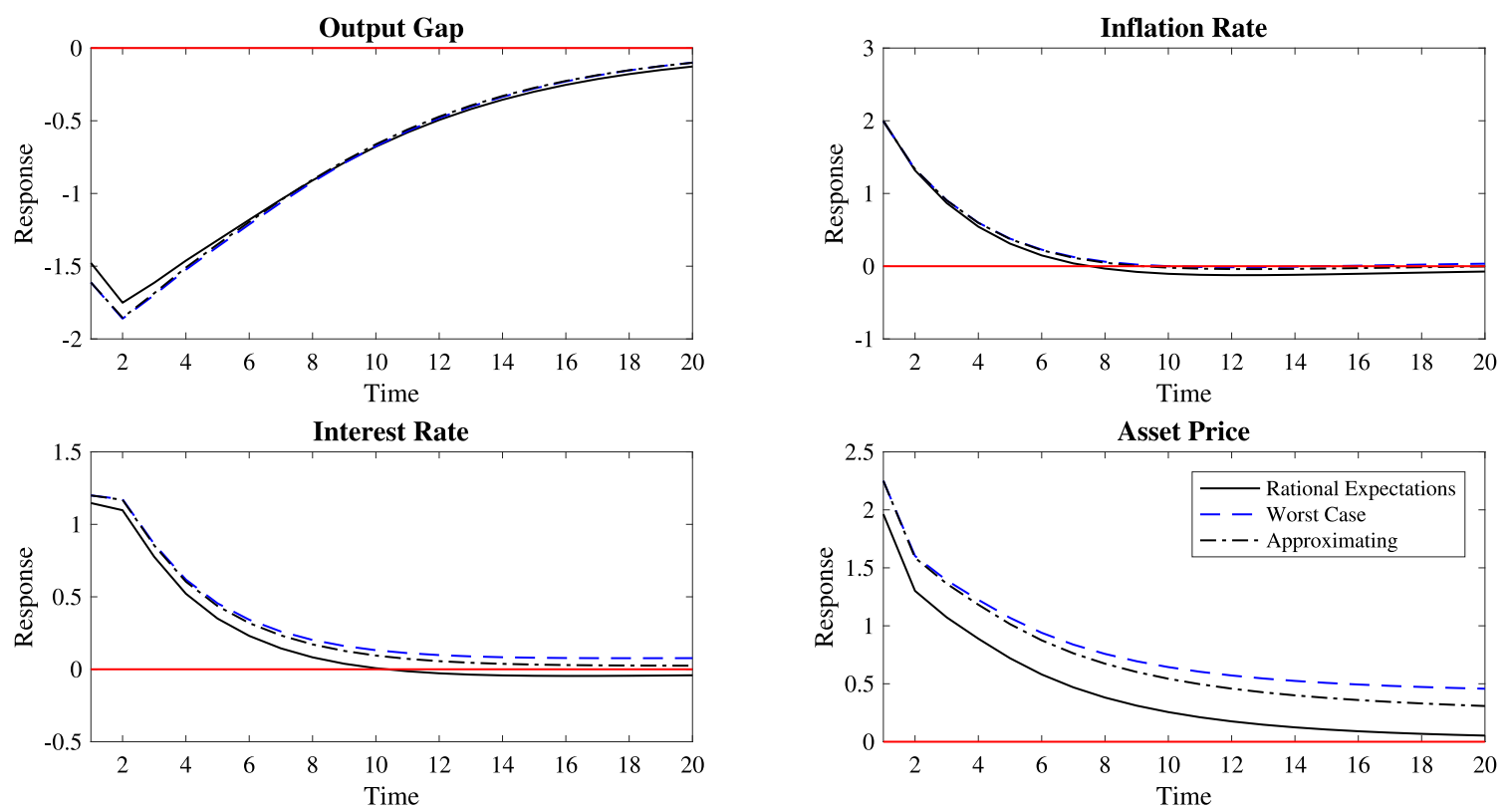

Fig. 2. Responses to cost-push shock.

positive wealth-effect on the output-gap, we observe a contraction due to the financial stabilization objective of the $C B$. The rise in the policy rate dominates the wealth-effect. Subsequently, price level goes down. However, the fall in the price level is limited due to the presence of effective financial wealth. ${ }^{4}$ Under model misspecification, policymaker overestimates the impact of the nonfundamental shock to the asset price. This induces a stronger response in the policy rate by allowing for higher deviations of output-gap and inflation from their steady states. Also, the impact of the shock lasts longer compared to the rational expectations case.

\footnotetext{
4 When the CB places smaller weight on output-gap stabilization or as $\psi \rightarrow 0$, initial negative response of inflation becomes stronger.
}

After a cost push shock, monetary authority responds by rising the interest rate, implying a fall in the output-gap. Due the stabilizing wealth-effect, i.e., the positive impact of marginal cost on expected real dividends, stock price increases. Once again, financial uncertainty amplifies the responses of the policy rate, output-gap, inflation and asset prices. The CB responds more since uncertainty proliferates the wealth-effect channel.

It is worth noting that we depart from Dai and Spyromitros (2012) by highlighting that the impact of financial uncertainty cannot be disregarded when the robust monetary authority commits and cares about financial stability. ${ }^{5}$

\footnotetext{
5 The result of aggressive monetary policy is preserved under different calibra-
} tion values of the relative weight of financial stability. 


\section{Conclusion}

This paper investigates robust optimal monetary policy under commitment when the $\mathrm{CB}$ is uncertain about the structure of the asset price. To do so, we assume a sticky price DSGE economy with perpetual-youth type demand-side. This heterogeneity assumption in the demand side of the economy attributes a critical role to financial stability in the model since fluctuations in the financial wealth affect real economy through the wealth-effect channel. Therefore, an optimal design of monetary policy entails incorporating financial stability as an additional target to inflation and output. Besides, the concern for asset-price equation uncertainty reinforces the idea of considering financial stability as an objective of the $\mathrm{CB}$.

This paper contributes to the literature from a theoretical point of view by designing an optimal monetary policy under commitment in the presence of uncertainty in the financial market. Unlike the existing studies that consider the design of monetary policy in this context, we focus on policy that have been formulated intentionally to guard against model misspecification.

The key finding is that model uncertainty speak to more active policymaking. In response to an asset-price shock, a robust policymaker allows output-gap and inflation to be more volatile compared to the model under rational expectations. Similarly, robustness reveals a more aggressive response to cost-push shock even though there is no uncertainty about the inflation equation.

To sum up, the results of the paper suggest that when robust $\mathrm{CB}$ observes a potential asset-price bubble, more aggressive policy is desirable if the policymaker takes into account the uncertainty surrounding the asset-price even at the cost of higher output and inflation volatility.

\section{Acknowledgment}

We thank the anonymous referee whose comments significantly improved the paper.

\section{References}

Anderson, Evan W., Hansen, Lars Peter, Sargent, Thomas J., 2003. A quartet of semigroups for model specification, robustness, prices of risk, and model detection. J. Eur. Econ. Assoc. 1 (1), 68-123, ISSN: 15424766, 15424774

Bernanke, Ben S., Gertler, Mark, 2001. Should central banks respond to movements in asset prices? Amer. Econ. Rev. 91 (2), 253-257. http://dx.doi.org/10.1257/aer 91.2.253, ISSN: 00028282.

Blanchard, Olivier J., 1985. Deficits, and finite horizons. J. Political Econ. 93 (2), 223 247. http://dx.doi.org/10.1086/261297.

Cecchetti, Stephen G., Genberg, Hans, Wadhwani, Sushil, 2002. Asset Prices in a Flexible Inflation Targeting Framework. Working Paper 8970, National Bureau of Economic Research.

Dai, Meixing, Spyromitros, Eleftherios, 2012. A note on monetary policy, asset prices, and model uncertainty. Macroecon. Dyn. 16 (5), 777-790. http://dx.doi. org/10.1017/S1365100510000787.

Galí, Jordi, 2014. Monetary policy and rational asset price bubbles. Amer. Econ. Rev. 104 (3), 721-752.

Gilchrist, Simon, Leahy, John V., 2002. Monetary policy and asset prices. J. Monetary Econ. 49 (1), 75-97.

Gürkaynak, Refet S., 2008. Econometric tests of asset price bubbles: Taking stock. J. Econ. Surv. 22 (1), 166-186. http://dx.doi.org/10.1111/j.1467-6419.2007. 00530.x.

Hansen, Lars Peter, Sargent, Thomas J., 2008. Robustness. Princeton University Press Lowe, Philip, Borio, Claudio, 2002. Asset Prices, Financial and Monetary Stability: Exploring the Nexus. BIS Working Papers 114, Bank for International Settlements.

Nistico, Salvatore, 2012. Salvatore nistico monetary policy and stock-price dynamics in a dsge framework. J. Macroecon. 34 (1), 126-146. http://dx.doi.org/10 1016/j.jmacro.2011.10.

Nistico, Salvatore, 2016. Optimal monetary policy and financial stability in A nonricardian economy. J. Eur. Econom. Assoc. 14 (5), 1225-1252.

Woodford, Michael, 2012. Inflation Targeting and Financial Stability. Working Paper 17967, National Bureau of Economic Research.

Yaari, Menahem E., 1965. Uncertain lifetime, life insurance, and the theory of the consumer. Rev. Econ. Stud. 32 (2), 137-150. http://dx.doi.org/10.2307/2296058. 